\title{
RETRACTED ARTICLE: Search for time variation of the fine-structure constant using $\left[\mathrm{O}_{\mathrm{III}}\right]$ emission lines
}

\author{
Le Duc Thong • Tran Van Hung • \\ Nguyen Thi Thu Huong $\cdot$ Ha Huy Bang
}

Received: 23 March 2010 / Accepted: 15 June 2010 / Published online: 12 August 2010

(C) Springer Science+Business Media B.V. 2010

This article has been published OnlineFirst, but is withdrawn due to following investigation of complaints received against it. In consultation with the author, both the author and the Editor in Chief Michael Dopita have agreed that substantial portions of the text came from other papers, most notably from Paolo Molaro et al. 2005, Proceedings IAU Symposium No. 232, without attribution, so this clearly constitutes plagiarism. It is clear that the author's lack of experience in publishing scientific papers led him to make this error. However, whatever the cause, plagiarism in any form cannot be countenanced. The Editor in Chief also notes that the other authors of the paper were unaware of the issue of plagiarism, and that no blame attaches to them.

\footnotetext{
L.D. Thong $(\bowtie)$

Ho Chi Minh City Institute of Physics, 01 Mac Dinh Chi Street, I Dist, Ho Chi Minh City, Vietnam

e-mail: ducthong@gmail.com
}

T.V. Hung

Research and Development Center for Radiation Technology, 202A Street 11, Linh Xuan Ward, Thu Duc District, Ho Chi Minh City, Vietnam

N.T.T. Huong $\cdot$ H.H. Bang

Laboratory for High Energy Physics and Cosmology, Faculty of Physics, Vietnam National University-Hanoi, 334 Nguyen Trai Street, Hanoi, Vietnam 